\title{
Wear Properties of Nanocomposite Traffic Marking Paint
}

\author{
Maryam Taheri ${ }^{1},{ }^{1}$ Mehdi Jahanfar, ${ }^{2}$ and Kenji Ogino ${ }^{3}$ \\ ${ }^{1}$ Graduate School Of Bio-Applications and System Engineering, Tokyo University of Agriculture and Technology, Koganei, \\ Tokyo 184, Japan \\ ${ }^{2}$ Faculty of Biological Sciences and Technology, Shahid Beheshti University, Tehran, Iran \\ ${ }^{3}$ Material Systems and Engineering, Tokyo University of Agriculture and Technology, 2-24-16 Nakacho, Koganei, Tokyo 184, Japan \\ Correspondence should be addressed to Maryam Taheri; m_taheri91@yahoo.com
}

Received 29 January 2018; Revised 23 April 2018; Accepted 4 June 2018; Published 15 July 2018

Academic Editor: Alessandro Pegoretti

Copyright @ 2018 Maryam Taheri et al. This is an open access article distributed under the Creative Commons Attribution License, which permits unrestricted use, distribution, and reproduction in any medium, provided the original work is properly cited.

\begin{abstract}
Durability and wear properties of traffic marking paints are one of the most important challenges in traffic management. This provides high-value cost-benefit, crowd reducing, improving journey times and decreasing environmental targets which are made by standing or slow-moving traffic. Because of the volume of traffic passing, climatic conditions, type of road surface, and drivers' behavior, a traffic marking paint gradually loses its basic properties such as durability and night visibility $\left(R_{\mathrm{L}}\right)$ that may potentially lead to accidents because of a loss of cognitive perception for drivers. Therefore, an effective wear resistance traffic marking paint is desirable to reduce wear, extending the lifetime and durability of paints. Analyzing this effect via microgranules, nanoclay application is the aim of this study. Clay/acrylic resin nanocomposite is synthesized using Cloisite ${ }^{\circledR} 30 \mathrm{~B}$ with different percentages. Finally, production of traffic marking paint nanocomposites with this nanocomposite acrylic resins can offer the promising prospect for these aims.
\end{abstract}

\section{Introduction}

In the world, the United States has the largest network of highways, including the urban and rural mileage. This network includes 6.7 million kilometers of streets, roads, and highways [1]. Annually, this transportation system carries at a level of $\$ 1116$ billion, close to $8 \%$ of the gross domestic product (GDP) [2]. For reasons, durability marking of this highway's networks is very important. These markings are the devices on a road surface that give guidance and information to drivers and pedestrians, thereby preventing confusions and uncertainty about their meaning that may potentially lead to accidents. So, effectiveness and uniformity of these markings should be ensured.

As no slowdown in transportation development is in vision in the near future, it is magisterial to introduce advanced technologies that can improve the efficiency of highway to ensure continuous development of the economy. So the importance of the national transportation network is well fixed, there is a growing distinction that highway operations require traffic marking paint. Because of the volume of traffic passing, climatic conditions, type of road surface, and drivers' behavior, a traffic marking paint gradually loses its basic properties such as durability and night visibility $\left(R_{\mathrm{L}}\right)$ that may potentially lead to accidents because of a loss of cognitive perception for drivers. Therefore, to extend the lifetime of paints, an effective wear and scratch resistance coating are useful.

In the recent years, the growth of new technologies and the extreme research activity in the field of coatings have resulted in the design of new products that combine common decorative and protective properties with original science. In addition to the many eventualities for improving organic coatings offered by grafting of functional groups, hybridization, and use of specific additives, the recent developments in nanotechnology have disclosed to the production of smart coatings. Nanosized and/or nanostructured particles, if correctly dispersed in coatings, can make products of wonderful properties and performances, directly or after activation by an external motive.

From the end of the last century, the discovery of different clays and their wide applications led to continuous 


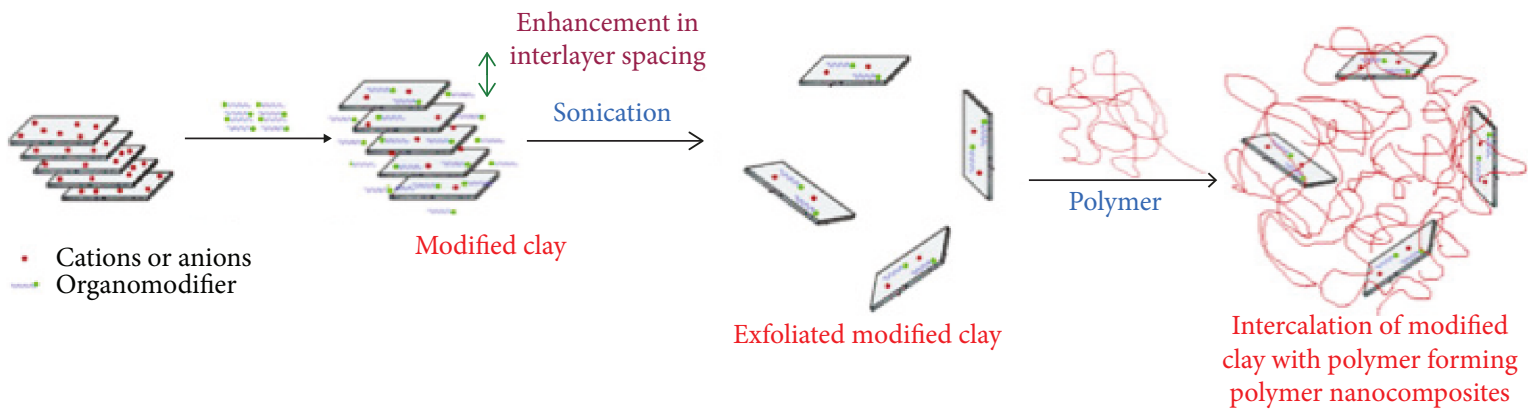

FIGURE 1: Schematic diagram of clay modification and production of polymer nanocomposite.

growth in nanotechnology. Clay refers to a class of materials generally made up of clay minerals or layered silicates with traces of metal oxides and organic material. Clay minerals are hydrous aluminum phyllosilicates, sometimes with variable contents of magnesium, iron, alkaline earth, alkali metals, and other cations, and are normally crystalline. Clays, as a low-cost inorganic material, are used in engineering, industrial, and scientific scopes. In industrial and engineering fields, clays are used in ceramics, oil drilling, and the paper industry $[3,4]$. In science, clays are commonly also used as adsorbents, decoloration agents, and catalysts. In this regard, clays have received considerable interest to affect the properties of polymer systems $[5,6]$. Commonly, clay particles have a lateral dimension in centimeters, the micron-sized in-plane dimension of the individual clay layers and the thickness of single clay platelets in the order of nanometers. These layered clays are characterized by strong intralayer covalent bonds within the individual sheets comprising the clay [7]. The efficiency of the clay to improve the properties of the polymer is primarily determined by the degree of its dispersion in the polymer matrix, which in turn depends on the clay particle size. But, the hydrophilic nature of the clay surfaces does not make a homogeneous dispersion in the organic phase of polymer. So, strong intralayer covalent bonds within the individual sheets make the weak dispersion of clays in the matrix during the production of polymer nanocomposites, commonly a modification of the clay is needed. Modification of clay may lead to improving dispersion of these materials in a solvent via intercalation with a polymer that provides enhancement of thermal and physical-mechanical properties of the nanocomposites, as shown in Figure 1. For the successful dispersion of nanoclay in the polymer, clay surface is treated to be hydrophobic. This is achieved by replacing the cations in the exchange layer between the plates with alkyl ammonium products [8, 9].

In order to insert clay into a polymer matrix, different methods such as solution intercalation $[10,11]$, melt mixing [12-15], and in situ polymerization techniques [15-17] can be applied.

In polymer/clay nanocomposites, two idealized structures are feasible: exfoliated and intercalated, as shown in Figure 2. In exfoliation, clay penetrates to the polymer matrix and randomly dispersed. Exfoliated nanocomposites create excellent property due to the large aspect ratio and surface

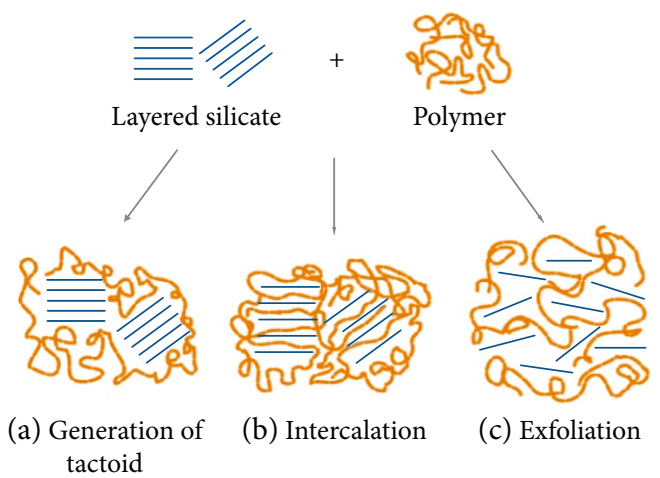

FIGURE 2: Usual ways of preparing clay/polymer nanocomposite.

area of the clay. The layer separation, especially exfoliation, depends on the establishment of desirable interactions between the clay surface and the polymer and the subsequent system energy reduction [18-22]. The exfoliated interaction improves the mechanical properties of nanocomposites, such as wear, scratch, impact, stiffness, dimensional stability, oxygen index, and gas permeability. By contrast, in intercalation, polymer chains penetrate into the interlayer region and interlayer expansion. The layer structures were detected by X-ray diffraction (XRD). Melt intercalation and in situ polymerization are two most usual ways for preparing clay nanocomposite. In melt intercalation, clay mixed with a molten polymer matrix. In in situ polymerization, monomer intercalation is followed by polymerization. The interaction between the monomer and the clay surface, the exfoliated nanocomposites (nylon-6 [23], poly ( $\varepsilon$-caprolactone) [24], and epoxy [25-29]) were successfully synthesized.

For in situ polymerization method, the increased spacing provides the monomer to penetrate into the gallery space and polymerize. This improved reinforcement of the polymer matrix and its properties.

Nanocomposites can be used as ideal candidates for many applications ranging from strong, heat-resistant automotive components to high-barrier packaging materials, aerospace, optical, electronic, and medical devices.

The impregnation technique of the clay by a vinyl monomer followed by its polymerization has been used in these 
cases [30-37]. However, since the adsorption of monomer molecules between the lamellae depends on the dipole moment of the monomer molecule, the yields of the physically inserted polymer were found to be low. The direct adsorption of uncharged linear polymers onto a clay surface has also been used for producing clay-polymer materials which depend on the adsorption of the hydration water molecules from the clay surfaces [38-41]. Since the sogained entropy prepares the driving force for this physical adsorption, it does not lead to high polymer. In addition, the polymers have been grafted to the available hydroxyl groups on the clay surface through coupling agents $[42,43]$. However, such surface modifications do not lead to the penetration of the polymers into the interlayer of the clay, and hence, they are not homogeneously dispersed.

Many thermoplastic polymers are produced by free radical polymerization using vinyl monomers, and the reaction adopts distinctly several mechanisms as compared to ringopening polymerization [44]. Polymerization is usually carried out in the presence of initiators. It is, therefore, necessary to check the interaction between the monomer, the initiator, and the modified clay surface in a systematic manner. Intercalated polymethyl methacrylate (PMMA) and polystyrene (PS) nanocomposites have been synthesized through either emulsion [45-48] or bulk polymerization $[49,50]$. The structural affinity between the styrene monomer and the organic cation played an important role in the PS/clay hybrid structure [51]. Improved dispersion of clay in the PMMA/ clay nanocomposites was obtained when methyl methacrylate was cointercalated and copolymerized with lauryl methacrylate (LMA) [52]. Efforts have also been made to anchor a living free radical polymerization (LFRP) initiator in the interlayer region to modify the intralayer polymerization rate and to achieve an exfoliated PS nanocomposite [53]. Recently, a more conventional initiator, $2,2^{\prime}$-azo (isobutyl amidine hydrochloride), was used to yield exfoliation of clay in the PMMA matrix, using suspension polymerization [54]. Exfoliation of clay in PMMA was also reported in the emulsion polymerization [55].

The research reported in this paper was aimed at the preparation and characterization of new formulations of nanoclay/acrylic resin and thereafter preparation and characterization of new formulations of traffic marking paint based on these resins. Acrylic resin is an extremely versatile polymer, largely used in cold-applied traffic marking paint with excellent film-forming properties, adhesion, good stability, reversibility, and nonyellowing characteristics. It is therefore of great interest to explore if it is possible to combine these properties with the wear and scratch resistance behavior.

This paper compares the specification of formulations of acrylic resin containing nanoclay by monitoring their distribution of nanoclay, optical property, the molecular weight $\left(M_{\mathrm{w}}\right)$, polydispersity index (PDI), solution viscosity, and mass conservation.

This paper compares the performances of different formulations of traffic marking paint containing nanocomposite acrylic resin by monitoring their wear resistance, scratch resistance, and $R_{\mathrm{L}}$.
TABLE 1: Characteristics of Cloisite 30B.

\begin{tabular}{lc}
\hline Clay & $\begin{array}{c}\text { Montmorillonite } \\
\text { Surface modifier }\end{array}$ \\
$\begin{array}{l}\text { Modifier concentration } \\
\text { (mequaternary ammonium }\end{array}$ & qua clay) \\
$\mathrm{d}_{001}\left(\mathrm{~A}^{\circ}\right)$ & 90 \\
\hline
\end{tabular}

$$
\begin{gathered}
\mathrm{CH}_{2} \mathrm{CH}_{2} \mathrm{OH} \\
\mathrm{CH}_{3}-\mathrm{N}^{+}-\mathrm{T} \\
\mathrm{CH}_{2} \mathrm{CH}_{2} \mathrm{OH}
\end{gathered}
$$$$
\mathrm{T} \text { is tallow }(\sim 65 \% \mathrm{C} 18 ; \sim 30 \% \mathrm{C} 16 ; \sim 5 \% \mathrm{C} 14) \text {, a fatty acid moiety }
$$

FIGURE 3: Chemical configuration of the organic modifier.

\section{Experimental}

2.1. Materials of Acrylic Resin. Methyl methacrylate (contains $\leq 30 \mathrm{ppm}$ MEHQ as inhibitor), butyl acrylate ( $\geq 99 \%$, contains $10-60 \mathrm{ppm}$ MEHQ as inhibitor), styrene ( $\geq 99.5 \%)$, and 2mercaptoethanol $(\geq 99 \%)$ were obtained from the Aldrich Chemical Co.

Dibenzoyl peroxide (Luperox A75) was obtained from Arkema Co. In most polymerizations of acrylic monomers, the polymerization temperature is greater than $100^{\circ} \mathrm{C}$ and the organic initiator is chosen so that the half-life time under the reaction conditions is in the range of 2 to 20 minutes.

Microgranule nanoclay based on a natural mineral was Cloisite 30B that is SWy-1 montmorillonite modified by MT2EtOH (methyl tallow bis-2-hydroxyethyl, quaternary ammonium) that obtained from BYK Additives \& Instruments with basal spacing $\mathrm{d}_{001} 1.85 \mathrm{~nm}$. Cloisite $30 \mathrm{~B}$ is microscaled in its delivery form and exfoliates down to nanoscale only in the matrix. Cloisite 30B with their organomodifier and other characteristics is provided in Table 1 . The chemical configuration of the organic modifier is shown in Figure 3.

Toluene $\left(>99.5 \%\right.$, boiling point $\left.=110^{\circ} \mathrm{C}\right)$ was obtained from Merck.

2.2. Materials of Traffic Marking Paint. To prepare the traffic marking paint, a copolymer acrylic resin, titanium dioxide (as a pigment), calcium carbonate (as a filler), solvent, and additives were used.

Thermoplastic acrylic resins were produced in this study. In nanocomposite acrylic resin, Cloisite $30 \mathrm{~B}$ was used as nanoclay.

Titanium dioxide is Ti-Pure ${ }^{\mathrm{TM}} \mathrm{R}-900$, manufactured by DuPont Co. in America.

Calcium carbonate was manufactured by Lorestan Chemical and Mineral Co. in Iran. The solvent is toluene (>99.5\%, Merck). The antisettling additive is Bentone 34, manufactured by Elementis Specialties Co. in Malaysia. The dispersing agent is Troysperse CD1, manufactured by Troy Co. in Canada. 
Medium grading drop on glass beads was produced by Baztab Rah Co. in Iran, according to BS EN 1423.

2.3. Synthesis of Acrylic Resins. Acrylic resins were prepared by conventional free radical solution polymerization techniques. The polymerizations were conducted under nitrogen in a jacketed, stainless steel reactor equipped with a mechanical stirrer, a thermometer with a temperature controller, and a reflux condenser. Table 2 presents weight percent of the main components for the preparation of the samples according to the experimental design of mixture method. Nanocomposite acrylic resins contain $1 \mathrm{wt} \%$ (a) and $2 \mathrm{wt} \%$ (b) Cloisite $30 \mathrm{~B}$.

The monomer feed and initiator were metered and charged into the reactor containing solvent and Cloisite $30 \mathrm{~B}$ at a prescribed temperature over a five-hour period. The chain transfer agent coexists in the monomer, prior to or at the initiation of polymerization, in an amount of $1 \mathrm{wt} \%$ at the most. Therefore, chain transfer agents (e.g., mercaptans) are needed to lower the molecular weight; however, mercaptan chain transfer agents can produce objectionable odors, color, and light instability in the coatings [56].

After the monomer and initiator addition was complete, the polymerization was continued for an additional hour. The monomer to solvent ratio was $3.7: 1$ (80\% solid, theoretical). Figure 4 illustrates production process of acrylic resin. After polymerization was completed, polymer was charged into the blender to adjust $60 \%$ solids with the solvent.

2.4. Preparation of Traffic Marking Paint. Table 3 presents weight percentage of the main components for the preparation of the samples according to the experimental design of mixture method. Figure 5 illustrates schematically production process of traffic marking paint. Antisettling additive and the dispersing agent were dispersed in acrylic resin for $10 \mathrm{~min}$. The pigment is then added to the dispersion that is then ball-milled using laboratory KREIS BASKET MILL/ KREIS-DISSOLVER (Niemann, Germany).

This operation continues until the fineness of grind paint is max 10 microns according to ISO 1524. Then, gradually add calcium carbonate and mix for $15 \mathrm{~min}$. With the solvent the viscosity is adjusted to $95-100 \mathrm{KU}$ according to test methods ISO 3219 and ASTM D562.

For wear resistance and scratch resistance tests, road marking samples were applied to aluminum substrates (according to test method ISO 1514), using a film applicator (Elcometer 3540/1, four-sided film application) according to test method ASTM D 823 practice E with a wet film thickness of $75 \mu \mathrm{m}$. The applied films were then allowed to dry at room temperature $\left(25 \pm 2^{\circ} \mathrm{C}\right)$ for $24 \mathrm{~h}$. The dry film thickness was $39-40 \mu \mathrm{m}$ (according to test method ISO 2808, method 10).

For measurement $R_{\mathrm{L}}$ of traffic marking samples, apply at least three lines of each specimen on clean asphalt with moderate traffic at $800 \mu$ wet film thickness, and then at this time, immediately add the glass beads $400 \mathrm{gr} / \mathrm{m}^{2}$ on the wet paints. The dry film thickness was $415-420 \mu \mathrm{m}$ (according to test method ISO 2808, method 10).
TABLE 2: Acrylic resin formulations.

\begin{tabular}{lccc}
\hline & \multicolumn{3}{c}{ Weight percent } \\
Raw materials & Acrylic resin & \multicolumn{2}{c}{$\begin{array}{c}\text { Nanocomposite } \\
\text { acrylic resin } \\
\text { a }\end{array}$} \\
\hline Methyl methacrylate & 20 & 19.8 & b \\
Butyl acrylate & 22.5 & 22 & 21.5 \\
Styrene & 13 & 12.7 & 12.5 \\
Acrylic acid & 1 & 1 & 1 \\
2-Mercaptoethanol & 0.5 & 0.5 & 0.5 \\
Dibenzoyl peroxide & 3 & 3 & 3 \\
Cloisite 30B & - & 1 & 2 \\
Solvent & 40 & 40 & 40 \\
\hline
\end{tabular}

All measures reported here represent an average of the results. Six measurements were performed in each test to calculate a suitable average value on three specimens.

2.5. Characterization of Acrylic Resins. In order to evaluate the distribution status of Cloisite $30 \mathrm{~B}$ on the resin, transmission electron microscope (TEM) images were recorded on a Philips CM-120, working at an accelerating voltage of $100 \mathrm{kV}$. The specimen was prepared onto carbon-coated copper grids and was imaged after the complete evaporation of the solvent.

X-ray diffraction (XRD) experiments were performed by Rigaku Ultima IV diffractometer, Japan, and intensity data were collected in the $2 \theta$ range of $0^{\circ}-25^{\circ}$ at a step of $0.02^{\circ}$ and a $2 \mathrm{sec}$ count time using $\mathrm{Cu}-\mathrm{K} \alpha$ radiation $\left(1.54 \mathrm{~A}^{\circ}\right)$ and a Ni filter, at $40 \mathrm{kV}$ and $50 \mathrm{~mA}$.

A UV-Vis spectrophotometer (Lambda 35, Perkin Elmer) was used to measure the difference of percentage of transmittance between the acrylic resin and nanocomposite acrylic resin films. The transmission signal was measured for the wavelength from 200 to $800 \mathrm{~nm}$ and then converted to an absorption signal for further evaluation.

Molecular weight and MWD of polymers can be measured by many different methods such as vapor phase osmometry, ultracentrifugation, and light scattering; the method used in this paper is gel permeation chromatography (GPC). The advantages of using GPC are the following: (1) has moderate cost, (2) has fast analysis time, (3) has excellent reproducibility of results, (4) can be applied to a wide variety of solvents and polymers, (5) can be applied to a wide range of molecular weights, and (6) has good agreement of results, particularly PDI, with results obtained from other techniques. The THF size exclusion chromatography (SEC) system consists of a Waters 1515 isocratic HPLC pump, a Waters 717 plus autosampler, a Waters 600E system controller (run by Breeze Version 3.30 SPA), and a Waters inline degasser AF. A Waters 2414 differential refractometer is connected in series with a Waters 2487 dual wavelength absorbance UV-Vis detector operating at variable wavelengths. Tetrahydrofuran (THF, HPLC grade, stabilized with $0.125 \%$ BHT, when using unstabilized THF, ensure that your solvent is fresh) as mobile phase is used at a flow rate of $1 \mathrm{ml} / \mathrm{min}$ under the operating temperature of $30^{\circ} \mathrm{C}$ and 


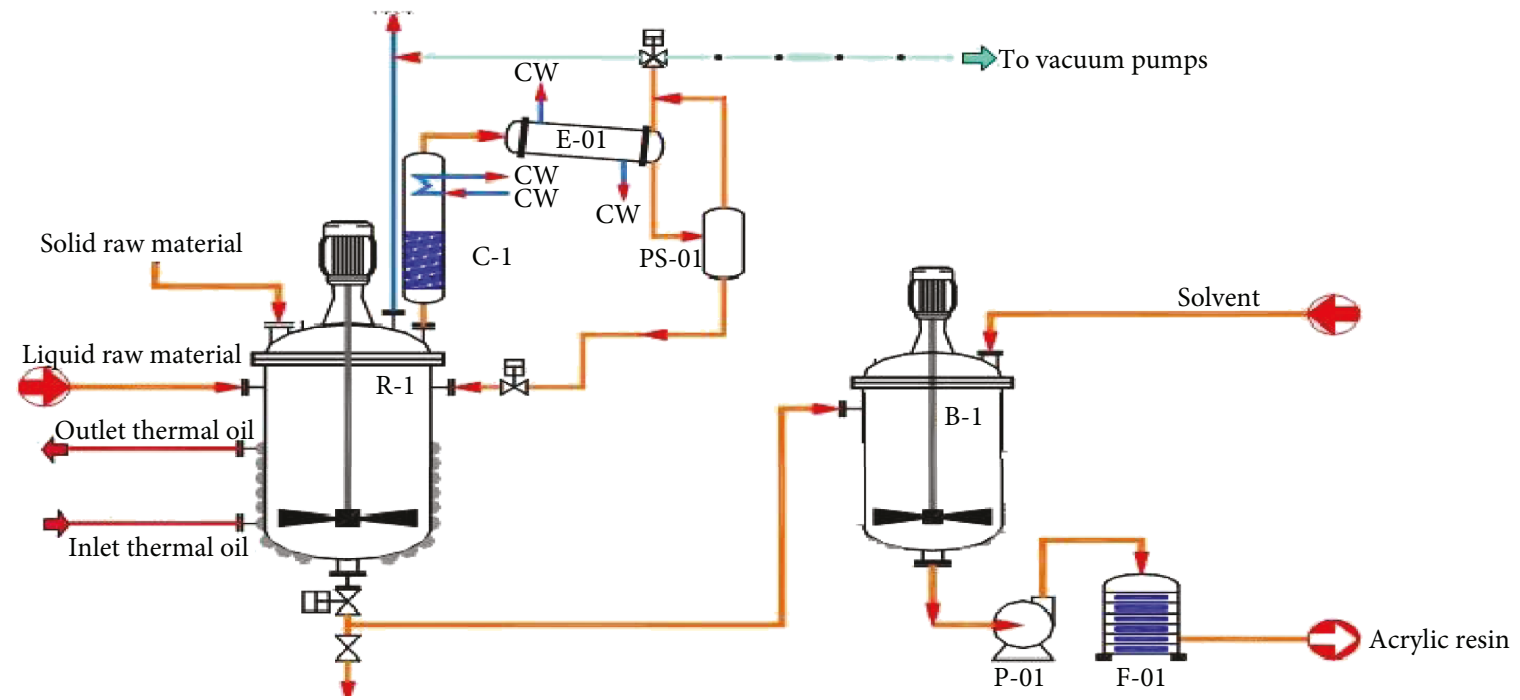

FIgURE 4: Production process of acrylic resin.

TABLE 3: Traffic marking paint formulations.

\begin{tabular}{lc}
\hline Raw materials & Weight percent \\
\hline Acrylic resin & 30 \\
Antisettling additives & 0.5 \\
Dispersing agent & 0.2 \\
Titanium dioxide & 10 \\
Calcium carbonate & 50 \\
Solvent & 10 \\
\hline
\end{tabular}

an injection volume of $100 \mu \mathrm{l}$. Two PLgel $5 \mu \mathrm{m}$ Mixed-C $(300 \times 7.5 \mathrm{~mm} /$ inner diameter: $7.5 \mathrm{~mm}$ and length: $300 \mathrm{~mm})$ columns and a precolumn PLgel $5 \mu \mathrm{m}$ Guard $(50 \times 7.5 \mathrm{~mm} /$ inner diameter: $7.5 \mathrm{~mm}$ and length: $50 \mathrm{~mm}$ ) are used. Calibration is done using polystyrene calibration kits of Agilent Technologies.

The viscosity of acrylic resins was determined using Brookfield DV-II+ Viscometer at $25^{\circ} \mathrm{C}$ according to test method ISO 2555.

Mass conservation based on the total polymer in the reaction mixture was measured using gravimetry. The resulting isolated copolymers were analyzed for cumulative polymer composition using a Bruker AMX500 and a Bruker MX300 Fourier Transform NMR spectrometer. The dried polymer was dissolved in deuterated chloroform $(\approx 2 \% w / v)$ at room temperature.

2.6. Characterization of Traffic Marking Paint. Wear resistance was determined by the test methods BS 6044 appendix $\mathrm{F}$ and ASTM D 968. In the referenced method, abrasive is poured on to a dry film on a glass panel until the paint is removed. A typical value for traffic marking paint is 651 of sand for the removal of a 3 mil $(75 \mu \mathrm{m})$ dry film.

Scratch resistance is done by test methods ISO 1518 and ASTM C1624. In the referenced method, under the increasing load, tipped needle hemispherically penetrates by scratching. In load, penetration of the needle to the substrate occurs, where the penetration of the needle may be either to the substrate or to an intermediate coat. Scratch resistance was performed using a Revetest ${ }^{\circledR}$ Scratch Tester $\left(\mathrm{RST}^{3}\right)$ from Anton Paar Co. Tests were carried out on a moving surface under the indenter for a scratch length of $3 \mathrm{~mm}$ and a max load range from $100 \mathrm{mN}$ to $100 \mathrm{~N}$.

The night and day visibility of road marking paints was measured with Retroreflectometer ZRM $1013^{+} R_{\mathrm{L}} / Q_{\mathrm{d}}$ of Zehntner Co., according to test method BS EN 1436.

\section{Results and Discussion}

\subsection{Results and Discussion of Acrylic Resins}

3.1.1. Distribution Cloisite 30B Nanoparticles. Typical TEM micrographs of nanocomposite acrylic resin with $1 \mathrm{wt} \%$ (a) and $2 \mathrm{wt} \%$ (b) Cloisite 30B have been shown in Figure 6. In this, the dispersion of Cloisite $30 \mathrm{~B}$ can be seen in the resin matrix. This morphology represents the exfoliated structure of the nanocomposite acrylic resin. The exfoliation of the clay in the nanocomposite acrylic resin was also confirmed by TEM. The dark lines show the existence of the silicate platelets in the polymer matrix.

The XRD studies were carried out on the Cloisite $30 \mathrm{~B}$ and the nanocomposites containing 1 and $2 \mathrm{wt} \%$ Cloisite $30 \mathrm{~B}$ to assess the degree of the intercalation of clay platelets in the resin and the formation of the nanocomposites. As shown in Figure 7, the curve of Cloisite 30B presents a broad peak at $2 \theta=4.753^{\circ}$, which indicates that the $d$-spacing between two silicate layers is about $1.857 \mathrm{~nm}$ (calculated using the Bragg's law $d=\lambda /[2 \sin (\theta)])$; the curve of nanocomposite acrylic resin/1 wt\% Cloisite 30B presents a broad peak at $2 \theta=2.868^{\circ}$, which indicates that the $d$-spacing between two silicate layers is about $3.083 \mathrm{~nm}$; and the curve of nanocomposite acrylic resin $/ 2 \mathrm{wt} \%$ Cloisite $30 \mathrm{~B}$ presents a broad peak at $2 \theta=2.856^{\circ}$, which indicates that the $d$-spacing between two silicate layers is about $3.089 \mathrm{~nm}$. Moreover, the resin molecules were intercalated into the Cloisite 30B layers 


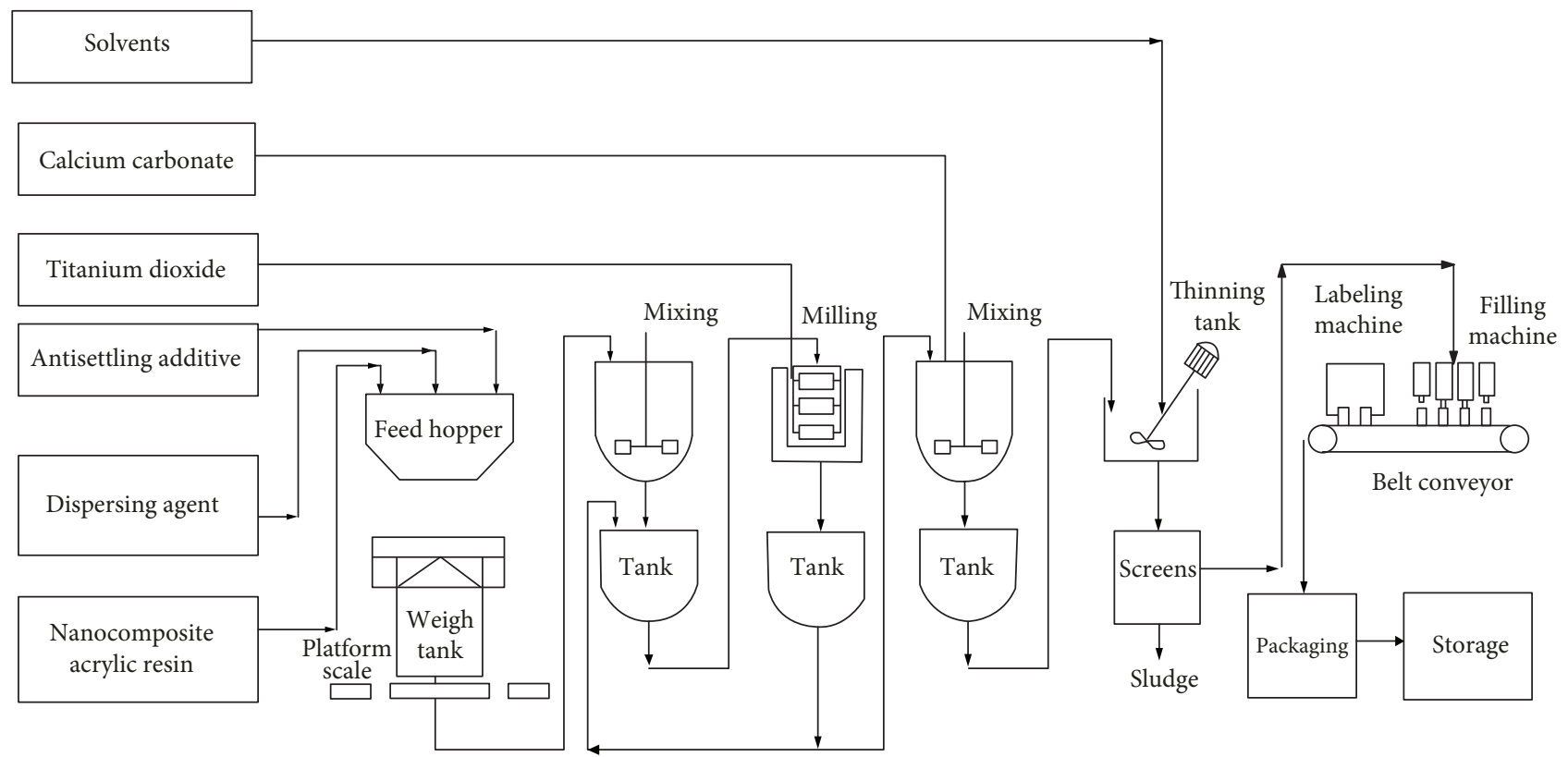

Figure 5: Production process of traffic marking paint.

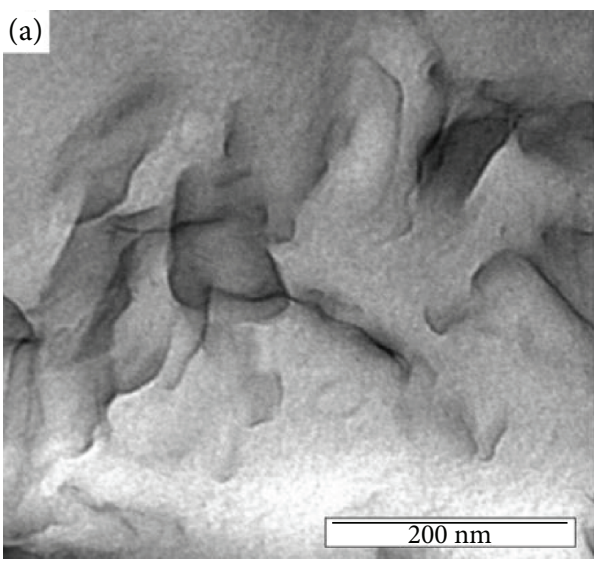

(a)

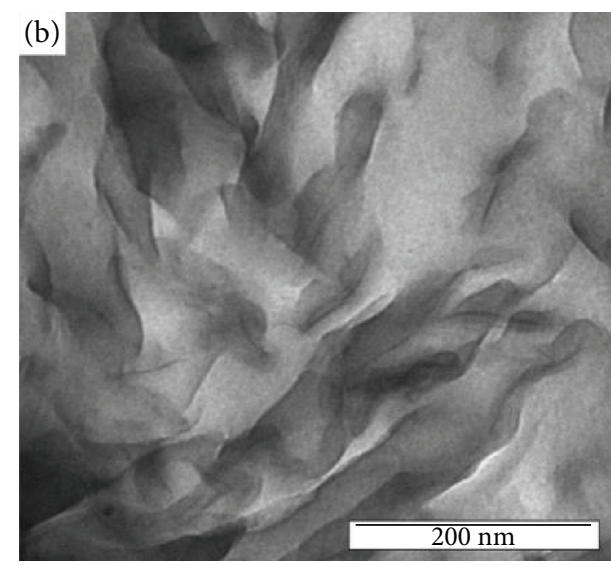

(b)

FIgURE 6: Typical TEM images of nanocomposite acrylic resins.

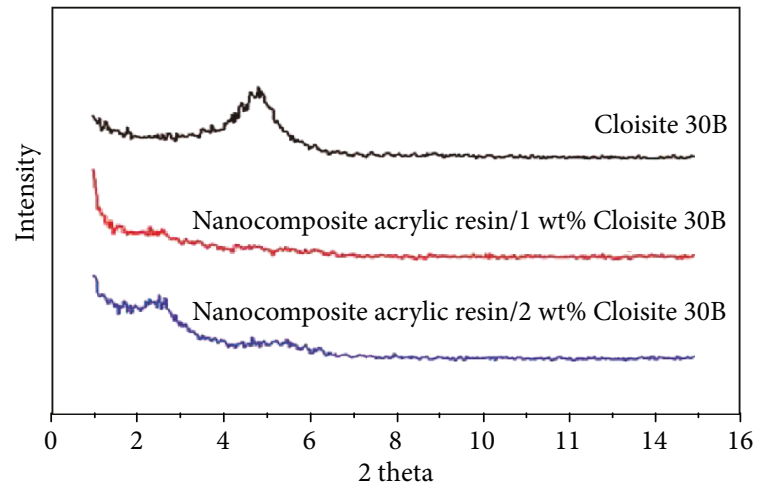

FIGURE 7: XRD patterns of Cloisite $30 \mathrm{~B}$ and nanocomposite acrylic resins. of the nanocomposites, because the $d$-spacing of clay was increased in the nanocomposite samples.

3.1.2. Optical Property. Figure 8(a) illustrates the difference of the percentage of transmittance between the acrylic resin and nanocomposite acrylic. In the visible range, acrylic resin is highly transparent and shows the energy absorption in the UV-B range (wavelengths lower than $320 \mathrm{~nm}$ ). Although the presence of Cloisite $30 \mathrm{~B}$ in the resin led to the decrease of both UV and visible lights transmittance, the reduction of UV transmittance was relatively higher than that of the visible light. At higher load of Cloisite 30B, the transmittance of UV and visible lights was lower. Figure 8(b) illustrates the percentage difference of transmittance between acrylic resin and nanocomposite acrylic resin. 


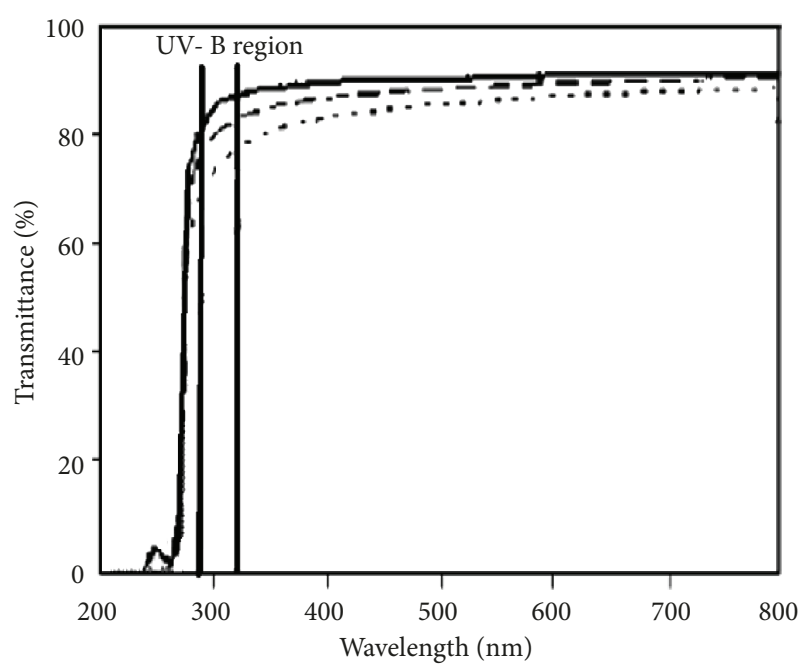

(一) Acrylic resin

(- - ) Nanocomposite acrylic resin with $1 \mathrm{wt} \%$ Cloisite 30B

(...) Nanocomposite acrylic resin with $2 \mathrm{wt} \%$ Cloisite $30 \mathrm{~B}$

(a)

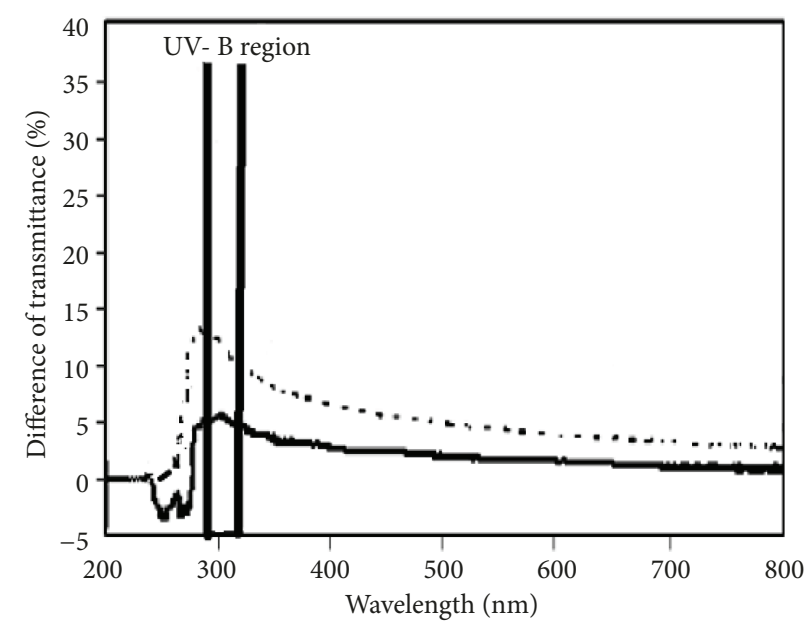

(-) Nanocomposite acrylic resin with $1 \mathrm{wt} \%$ Cloisite 30B

$(--)$ Nanocomposite acrylic resin with $2 \mathrm{wt} \%$ Cloisite $30 \mathrm{~B}$

(b)

FIGURE 8: Optical property: (a) UV-visible transmittance of acrylic resin and nanocomposite acrylic resin films and (b) the difference of UV-visible transmittance between acrylic resin and nanocomposite acrylic resin.

3.1.3. $M_{\mathrm{w}}$ Study. The primary factors that influence the molecular weight properties of acrylic resins and the efficiency of the polymerization are the initiator concentration, initiator type, radicals produced, the rate of initiator decomposition, the polymerization temperature, the solvent type, monomer mix, nanoclay existence, and feed rate of monomers and initiator. In this study, the initiator concentration, initiator type, the polymerization temperature, the solvent type, monomer mix, and feed rate of monomers and initiator are fixed. Therefore, nanoclay existence, radicals produced, and the rate of decomposition of the initiator are the dominant factors in controlling the molecular weight. To a large extent, the effect of nanoclay on the decomposition rate of initiator controls the overall polymerization efficiency. Table 4 illustrates $M_{\mathrm{w}}$ of acrylic resins. By using Cloisite $30 \mathrm{~B}$, there is a significant increase of $M_{\mathrm{w}}$ in acrylic resin. It can be concluded from the results of $M_{\mathrm{w}}$ study that around $3.8 \%$ and $5.8 \%$, rising of $M_{\mathrm{w}}$ with incorporating of $1 \%$ and $2 \%$ nanoclay into the polymeric matrix, respectively, were observed.

3.1.4. PDI Study. The $\mathrm{H}$-abstraction ability of the free radicals generated from the initiator plays a major role in determining the PDI. Dibenzoyl peroxide initially cleaves at the oxygen-oxygen bond; other bond cleavages can and do occur either simultaneously with or sequencers to the oxygenoxygen bond dissociation. The relative stability of the $R$ radical determines whether peroxide undergoes single- or multiple-bond homolysis. Table 5 illustrates PDI of acrylic resins. It can be concluded from the results of PDI study that around $4.1 \%$ and $6.5 \%$, rising of PDI with incorporating of $1 \%$ and $2 \%$ nanoclay into the polymeric matrix, respectively, were observed.
TABLe 4: $M_{\mathrm{W}}$ of acrylic resins.

\begin{tabular}{lccc}
\hline $\begin{array}{l}\text { Measurement } \\
\text { number }\end{array}$ & Acrylic resin & $\begin{array}{r}M_{\mathrm{W}}(\mathrm{g} / \mathrm{mol}) \\
\text { Nanocomposite } \\
\text { acrylic resin (a) }\end{array}$ & $\begin{array}{c}\text { Nanocomposite } \\
\text { acrylic resin (b) }\end{array}$ \\
\hline 1 & 70746 & 73448 & 74851 \\
2 & 70753 & 73453 & 74852 \\
3 & 70749 & 73447 & 74852 \\
4 & 70749 & 73453 & 74848 \\
5 & 70751 & 73451 & 74847 \\
6 & 70753 & 73448 & 74850 \\
Mean & $\mathbf{7 0 7 5 0}$ & $\mathbf{7 3 4 5 0}$ & $\mathbf{7 4 8 5 0}$ \\
Standard & $\mathbf{2}$ & $\mathbf{2}$ & $\mathbf{2}$ \\
deviation & & & \\
\hline
\end{tabular}

3.1.5. Viscosity Study. In this case, the viscosity of the acrylic resin is compared with nanocomposite acrylic resin. Table 6 illustrates viscosity of acrylic resins. By using Cloisite 30B, there is a significant increase of viscosity in acrylic resin, so pure acrylic resin has lower viscosity rather than nanocomposite acrylic resins. It can be concluded from the results of viscosity study that around $48 \%$ and $67 \%$, rising of viscosity with incorporating of $1 \%$ and $2 \%$ nanoclay into the polymeric matrix, respectively, were observed.

3.1.6. Mass Conservation Study. Dibenzoyl peroxide (the initiator) can be decomposed rapidly at the reaction temperature, generating free radicals. The free radicals are mainly consumed through at tacking the reactive $\mathrm{C}-\mathrm{C}$ bonds in the propagation stage of copolymerization. All spectra exhibited good peak separations for diagnostic signals. Figure 9 
TABLe 5: PDI of acrylic resins.

\begin{tabular}{lccc}
\hline $\begin{array}{l}\text { Measurement } \\
\text { number }\end{array}$ & Acrylic resin & $\begin{array}{c}\text { PDI } \\
\text { Nanocomposite } \\
\text { acrylic resin (a) }\end{array}$ & $\begin{array}{c}\text { Nanocomposite } \\
\text { acrylic resin (b) }\end{array}$ \\
\hline 1 & 1.682 & 1.761 & 1.784 \\
2 & 1.684 & 1.738 & 1.796 \\
3 & 1.674 & 1.746 & 1.796 \\
4 & 1.680 & 1.751 & 1.793 \\
5 & 1.681 & 1.750 & 1.785 \\
6 & 1.680 & 1.758 & 1.786 \\
Mean & $\mathbf{1 . 6 8 0}$ & $\mathbf{1 . 7 5 0}$ & $\mathbf{1 . 7 9 0}$ \\
Standard & & & $\mathbf{0 . 0 0 5}$ \\
deviation & $\mathbf{0 . 0 0 3}$ & $\mathbf{0 . 0 0 8}$ & \\
\hline
\end{tabular}

TABLe 6: The viscosity of acrylic resins.

\begin{tabular}{lccc}
\hline $\begin{array}{l}\text { Measurement } \\
\text { number }\end{array}$ & Acrylic resin & $\begin{array}{c}\text { Viscosity (cP) } \\
\text { Nanocomposite } \\
\text { acrylic resin (a) }\end{array}$ & $\begin{array}{c}\text { Nanocomposite } \\
\text { acrylic resin (b) }\end{array}$ \\
\hline 1 & 3298 & 4902 & 5500 \\
2 & 3303 & 4896 & 5496 \\
3 & 3304 & 4897 & 5500 \\
4 & 3300 & 4902 & 5502 \\
5 & 3298 & 4900 & 5500 \\
6 & 3297 & 4903 & 5502 \\
Mean & $\mathbf{3 3 0 0}$ & $\mathbf{4 9 0 0}$ & $\mathbf{5 5 0 0}$ \\
Standard & $\mathbf{3}$ & $\mathbf{3}$ & $\mathbf{2}$ \\
deviation & & &
\end{tabular}

illustrates that the signal at $\approx 4.0 \mathrm{ppm}$ was due to the $-\mathrm{OCH}_{2}$ group in $\mathrm{BA}$, another signal at $\approx 3.6 \mathrm{ppm}$ was associated with the $-\mathrm{OCH}_{3}$ group of MMA, and another signal at $\approx 6.4-7.1 \mathrm{ppm}$ was associated with the aromatic region of STY. The relative mole fractions of monomer bound in the polymer $\left(F_{\mathrm{BA}}\right.$ or $\left.F_{\mathrm{MMA}}\right)$ were determined from the areas under the corresponding peaks.

The structure of layered silicates consists of two fused silica tetrahedral sheets sandwiching an edge-shared octahedral sheet of either aluminum or magnesium hydroxide. Isomorphous substitutions of $\mathrm{Si}^{4+}$ for $\mathrm{Al}^{3+}$ in the tetrahedral lattice and $\mathrm{Al}^{3+}$ for $\mathrm{Mg}^{2+}$ in the octahedral sheet cause an excess of negative charges within montmorillonite layers. These negative charges are counterbalanced by cations such as $\mathrm{Ca}^{2+}$ and $\mathrm{Na}^{+}$situated between the layers. In Cloisite $30 \mathrm{~B}$, the clay layers are intercalated by long chain alkylammonium ions. So, the Cloisite 30B does not change the reaction mechanism and therefore does not affect the structure formation of copolymer during polymerization. But the Cloisite 30B mainly affects the initiation stage, so the mass conservation in nanocomposite acrylic resin was higher than acrylic resin. Figure 10 illustrates mass conservation of acrylic resins. It can be concluded from the results of mass conservation study that around $0.5 \%$ and $1 \%$, rising of mass conservation with incorporating of $1 \%$ and $2 \%$ nanoclay into the polymeric matrix, respectively, were observed.

Totally, Table 7 compares $M_{\mathrm{W}}$, PDI, solution viscosities, and mass conservation of acrylic resins and nanocomposite acrylic resins.

\subsection{Results and Discussion of Traffic Marking Paint}

3.2.1. Resistance to Wear Study. Resistance to wear is a measure of the ability of the dried film to withstand wear from traffic and from objects rolled or pulled across the surface. Table 8 illustrates resistance to wear of traffic marking paints. It can be concluded from the results of wear study that around $72 \%$ and $107 \%$ improvement in wear resistance property of traffic marking paints a and b, respectively, was observed. Figure 11 shows the wear morphology of the coatings under a normal load of $70 \mathrm{l}$ abrasive. No severe wear was found in nanocomposite traffic marking paint a.

3.2.2. Scratch Resistance Study. In a scratch test, some information about traffic marking paints such as residual depth, as a function of the applied load, are achievable. The residual depth shows the degree of scratch resistance. Figure $12 \mathrm{com}$ pares the residual depth of marking paints. Traffic paint shows very weak scratch resistance, as reflected by a sharp increase in residual depth at low applied loads. For nanocomposite traffic marking paints, the increase in residual depth by an applied force depends on the clay content. However, nanocomposite traffic paint a shows a very slow increase in residual depth, with applied loads $>2500 \mathrm{mN}$ which can be seen at the lowest slope. For nanocomposite traffic marking paint $b$ at loadings $<1500 \mathrm{mN}$, a relatively lower slope can be seen. It can be concluded from the results of scratch study that scratch resistance of nanocomposite traffic marking paint $b$ is higher than nanocomposite traffic marking paint $a$.

3.2.3. $R_{\mathrm{L}}$ Study. Measuring of road marking paint gives the driver an inside look about road and in order to secure it. According to measurement results, retroreflection below minimum levels is not acceptable. Minimum values of retroreflection according to BS EN 1436 at different times (zero, after 3, 6, and 9 months) presented in Table 9.

With passing cars tires, due to the impact effect of the friction, large sizes of glass beads are removed. Over time, due to the wearability of the paint, small glass beads on the paint surface begin to appear. Finally, night visibility decreases due to removal of small glass beads. For having night visibility at a long time, traffic marking paint should be wear resistant. As wear decreases, small glass beads adhere to the surface paint and night visibility increases. Retroreflection of samples over a specified period is illustrated in Figure 13. It can be concluded from the results of $R_{\mathrm{L}}$ the improvement of $R_{\mathrm{L}}$ property of nanocomposite traffic marking paints $\mathrm{a}$ and $\mathrm{b}$ rather than traffic marking paint. The improvement rate in $2 \mathrm{wt} \%$ Cloisite $30 \mathrm{~B}$ is highest. It is necessary to mention that $R_{\mathrm{L}}$ of traffic marking paint at 6 and 9 months after zero time decreases below minimum levels that is not acceptable and it is fined. 


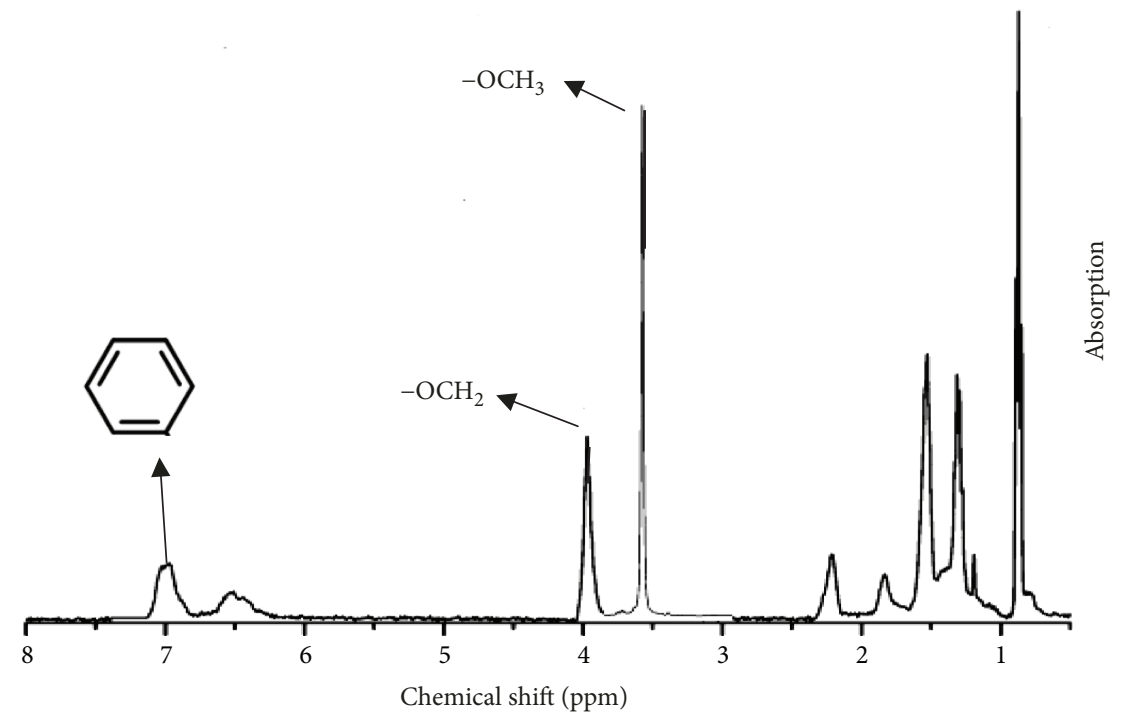

FIGURE 9: HNMR of acrylic resins.

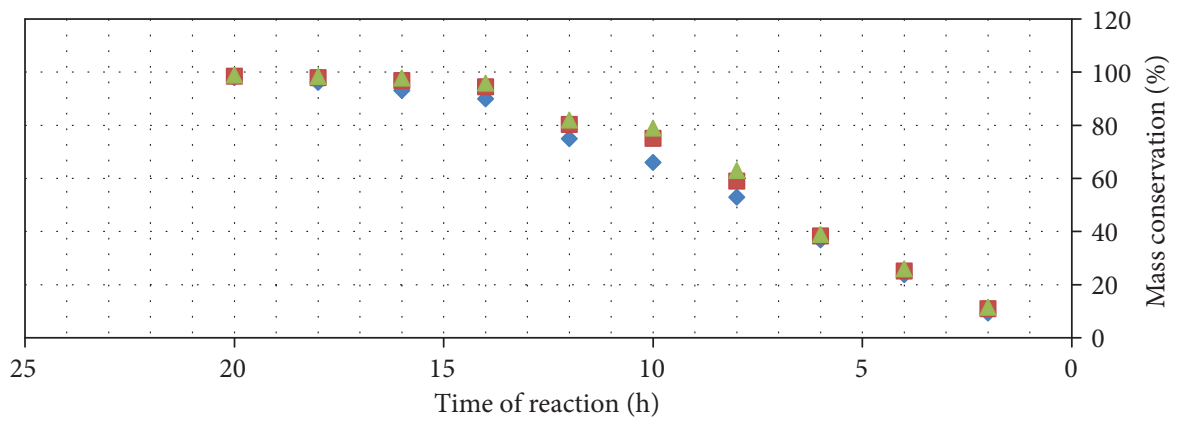

- Acrylic resin

- Nanocomposite acrylic resin (a)

$\triangle$ Nanocomposite acrylic resin (b)

Figure 10: The mass conservation of acrylic resins.

TABLE 7: $M_{\mathrm{w}}$, PDI, viscosity, and mass conservation properties of acrylic resins.

\begin{tabular}{lccc}
\hline & \multicolumn{3}{c}{ Code of resin } \\
Specifications & Acrylic resin & \multicolumn{2}{c}{$\begin{array}{c}\text { Nanocomposite } \\
\text { acrylic resin } \\
\text { a }\end{array}$} \\
& & 103 & b \\
\hline Reaction temperature $\left({ }^{\circ} \mathrm{C}\right)$ & 103 & 73450 & 74850 \\
$M_{\mathrm{w}}(\mathrm{g} / \mathrm{mol})$ & 70750 & 1.75 & 1.79 \\
PDI & 1.68 & 4900 & 5500 \\
Viscosity $(\mathrm{cP})$ & 3300 & 98.5 & 99 \\
$\begin{array}{l}\text { Mass conservation } \\
\text { (after 20 h of the reaction) }\end{array}$ & 98 & & \\
\hline
\end{tabular}

\section{Conclusion}

Nanoclay-based traffic marking paints are wear and scratch resistant. Different formulations, including the different
TABLE 8: Resistance to wear of traffic marking paints.

\begin{tabular}{lccc}
\hline $\begin{array}{l}\text { Measurement } \\
\text { number }\end{array}$ & $\begin{array}{c}\text { Acrylic } \\
\text { resin }\end{array}$ & $\begin{array}{c}\text { Wear resistance (l) } \\
\text { acrylic resin (a) }\end{array}$ & $\begin{array}{c}\text { Nanocomposite } \\
\text { acrylic resin (b) }\end{array}$ \\
\hline 1 & 72.1 & 123.2 & 148.4 \\
2 & 72 & 123.2 & 148.2 \\
3 & 71.5 & 123 & 148.2 \\
4 & 71.2 & 123 & 148.4 \\
5 & 71.3 & 123 & 148.55 \\
6 & 70.9 & 123.1 & 148.7 \\
Mean & $\mathbf{7 1}$ & $\mathbf{1 2 3}$ & $\mathbf{1 4 8}$ \\
Standard & $\mathbf{0 . 4}$ & $\mathbf{0 . 1}$ & $\mathbf{0 . 2}$ \\
deviation & & &
\end{tabular}

percentages of Cloisite $30 \mathrm{~B}$ in resin formulations, were developed and tested in order to assess the effects on wear and scratch resistance and $R_{\mathrm{L}}$ study of road marking paints. 


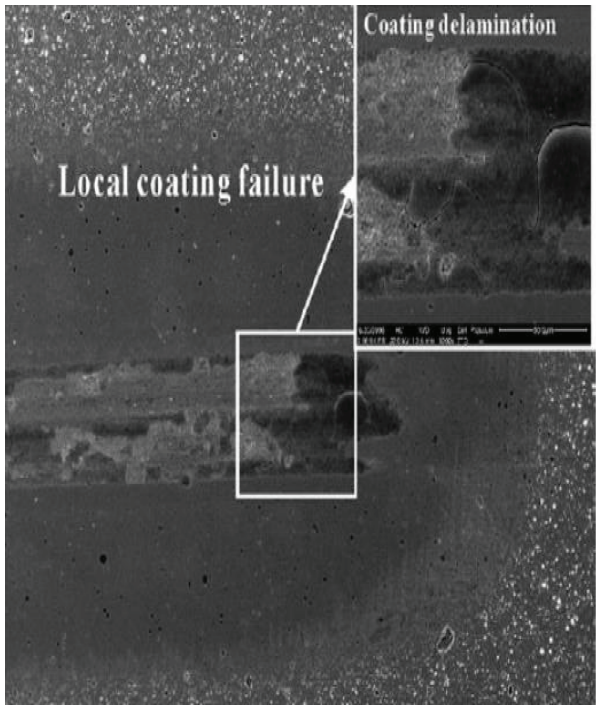

(a)

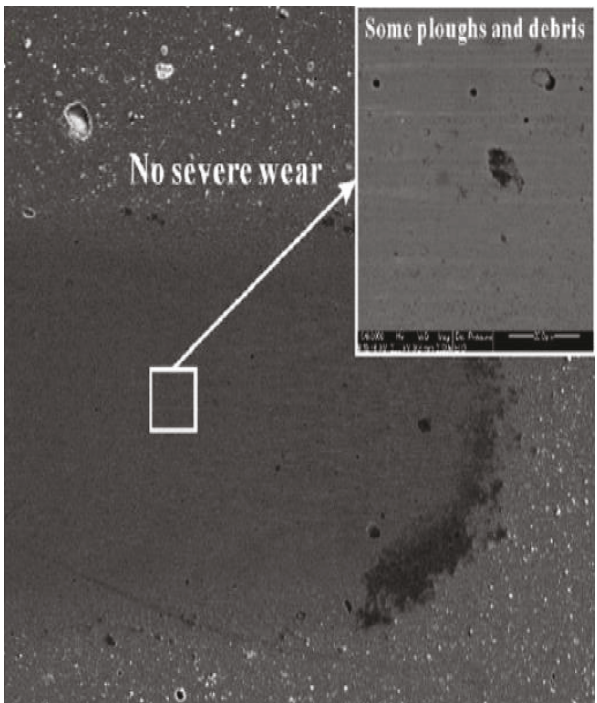

(b)

FIGURE 11: The wear morphology of the coatings: (a) traffic marking paint and (b) nanocomposite traffic marking paint a, under a normal load of 701 abrasive.

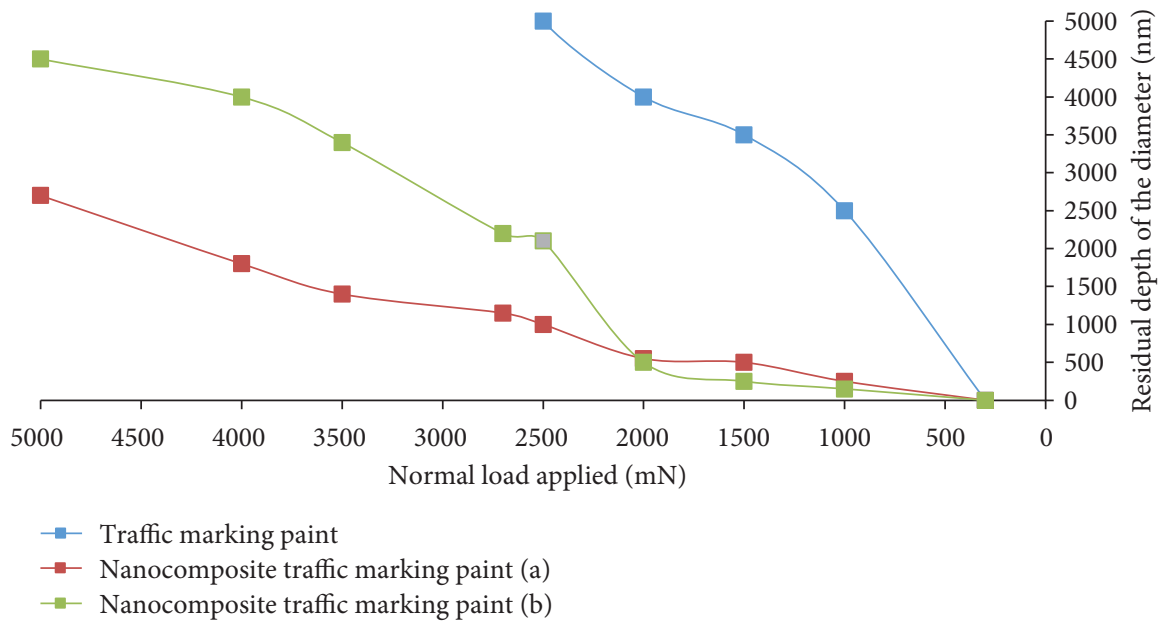

FIGURE 12: Residual depth-normal load variation.

TABLE 9: Minimum values of night visibility of road marking paints at the different times (BS EN 1436).

\begin{tabular}{lc}
$\begin{array}{l}\text { Measurement time of } \\
\text { night visibility }\end{array}$ & $\begin{array}{c}\text { Night visibility }\left(R_{\mathrm{L}}\right) \text { at } \\
\text { dry road }\end{array}$ \\
\hline Zero & $\geq 150$ \\
3 months after zero & $\geq 135$ \\
6 months after zero & $\geq 120$ \\
9 months after zero & $\geq 75$ \\
\hline
\end{tabular}

The TEM and XRD confirmed the exfoliation and the intercalation of clay platelets in the nanocomposite acrylic resin containing $1 \mathrm{wt} \%$ and $2 \mathrm{wt} \%$ Cloisite 30B. The effect of Cloisite $30 \mathrm{~B}$ on polymerization and behavior of acrylic resin was quite obvious. The results showed that Cloisite
30B increases $M_{\mathrm{w}}, \mathrm{PDI}$, and viscosity and speeds up the mass conservation at both $1 \mathrm{wt} \%$ and $2 \mathrm{wt} \%$ clay loading levels. Change rate is highest in $2 \mathrm{wt} \%$ Cloisite $30 \mathrm{~B}$.

The characterization of the new road marking paints was focused on features, such as wear resistance, scratch resistance, and $R_{\mathrm{L}}$ changes. Improvement in wear and scratch resistance is due to the presence of Cloisite 30B because of the following:

(1) Cloisite 30B acts as a barrier and also prevents largescale fragmentation of polymer matrix.

(2) Cloisite 30B acts as a reinforcing element, bears the load, and improves wear and scratch resistance.

(3) Due to the existence of two phases (soft polymer phase and clay-reinforced hard phase), the region in 


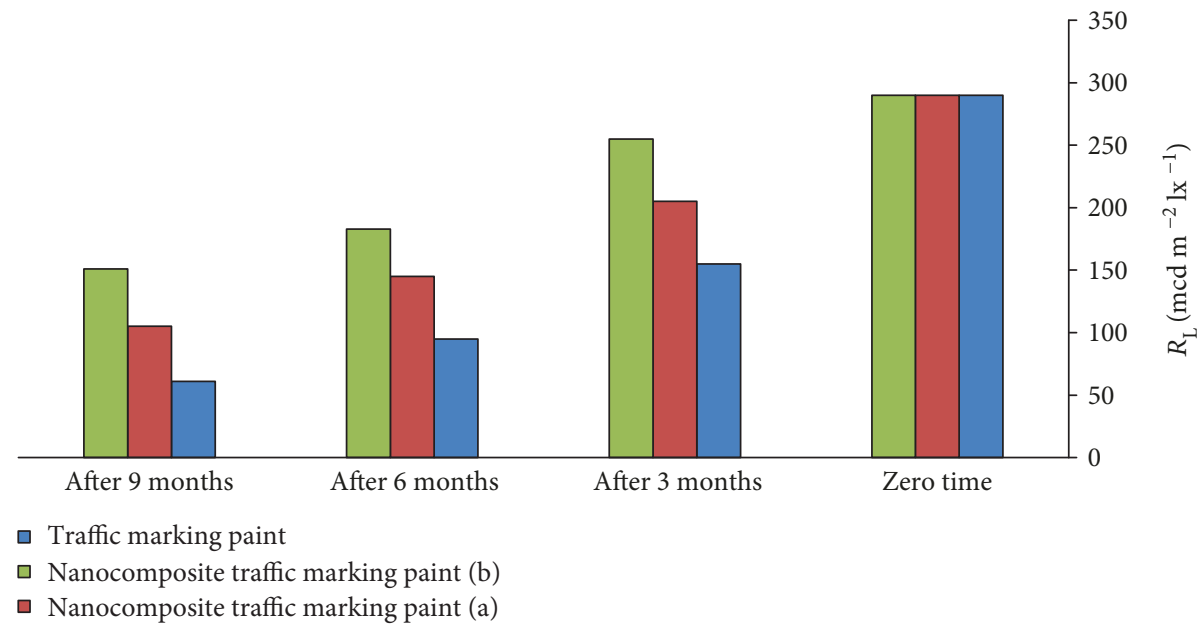

Figure 13: Change in $R_{\mathrm{L}}$ versus time.

soft phase can be removed easily compared to that of the hard phase. With increase of Cloisite 30B, wear and scratch resistance will be improved.

Finally, the results of the study suggest that clay intercalated morphology likely contributes to the improvement of wear and scratch resistance and $R_{\mathrm{L}}$. In this context, improvement rate in $2 \mathrm{wt} \%$ Cloisite $30 \mathrm{~B}$ is highest.

\section{Data Availability}

The data used to support the findings of this study are available from the corresponding author upon request.

\section{Conflicts of Interest}

The authors declare that they have no conflicts of interest.

\section{Acknowledgments}

This project was supported by the Reef Chemical \& Industrial Group.

\section{References}

[1] Table 1-5: U.S. Publica Road and Street Mileage by Functional System (a), US Bureau of Transportation Statistics, 2016, Retrieved 2017-04-12.

[2] US Department of Commerce and Bureau of Economic Analysis, National Income and Product Accounts Tables, BEA publisher, 2016.

[3] H. H. Murray, "Overview - clay mineral applications," Applied Clay Science, vol. 5, no. 5-6, pp. 379-395, 1991.

[4] J. T. Kloprogge, "Synthesis of smectites and porous pillared clay catalysts: a review," Journal of Porous Materials, vol. 5, no. 1, pp. 5-41, 1998.

[5] B. K. G. Theng, The Chemistry of Clay-Organic Reactions, Hilger, London, UK, 1974.

[6] B. K. G. Theng, Formation and Properties of Clay-Polymer Complexes, Elsevier, Amsterdam, Netherlands, 1979.
[7] M. Okamoto, "Recent advances in polymer/layered silicate nanocomposites: an overview from science to technology," Materials Science and Technology, vol. 22, no. 7, pp. 756779, 2006.

[8] A. B. Morgan and J. D. Harris, "Exfoliated polystyrene-clay nanocomposites synthesized by solvent blending with sonication," Polymer, vol. 45, no. 26, pp. 8695-8703, 2004.

[9] Y. Li and H. Ishida, "Solution intercalation of polystyrene and the comparison with poly(ethyl methacrylate)," Polymer, vol. 44, no. 21, pp. 6571-6577, 2003.

[10] S. Sinha Ray and M. Okamoto, "Polymer/layered silicate nanocomposites: a review from preparation to processing," Progress in Polymer Science, vol. 28, no. 11, pp. 15391641, 2003.

[11] X. Kornmann, L. A. Berglund, J. Sterte, and E. P. Giannelis, "Nanocomposites based on montmorillonite and unsaturated polyester," Polymer Engineering \& Science, vol. 38, no. 8, pp. 1351-1358, 1998.

[12] V. Causin, C. Marega, A. Marigo, and G. Ferrara, “Assessing organo-clay dispersion in polymer layered silicate nanocomposites: a SAXS approach," Polymer, vol. 46, no. 23, pp. 9533-9537, 2005.

[13] N. Moussaif and G. Groeninckx, "Nanocomposites based on layered silicate and miscible PVDF/PMMA blends: melt preparation, nanophase morphology and rheological behaviour," Polymer, vol. 44, no. 26, pp. 7899-7906, 2003.

[14] Z.-M. Liang and J. Yin, "Poly(etherimide)/montmorillonite nanocomposites prepared by melt intercalation," Applied Polymer Science, vol. 90, no. 7, pp. 1857-1863, 2003.

[15] M. Krajnc and U. Šebenik, "Poly(methyl methacrylate)/ montmorillonite nanocomposites prepared by bulk polymerization and melt compounding," Polymer Composites, vol. 30, no. 11, pp. 1678-1686, 2009.

[16] P. Uthirakumar, K. S. Nahm, Y. B. Hahn, and Y. S. Lee, "Preparation of polystyrene/montmorillonite nanocomposites using a new radical initiator-montmorillonite hybrid via in situ intercalative polymerization," European Polymer Journal, vol. 40, no. 11, pp. 2437-2444, 2004.

[17] A. Kiersnowski and J. Piglowski, "Polymer-layered silicate nanocomposites based on poly (E-caprolactone)," European Polymer Journal, vol. 40, no. 6, pp. 1199-1207, 2004. 
[18] R. A. Vaia and E. P. Giannelis, "Lattice model of polymer melt intercalation in organically-modified layered silicates," Macromolecules, vol. 30, no. 25, pp. 7990-7999, 1997.

[19] R. A. Vaia and E. P. Giannelis, "Polymer melt intercalation in organically-modified layered silicates: model predictions and experiment," Macromolecules, vol. 30, no. 25, pp. 80008009, 1997.

[20] A. C. Balazs, C. Singh, and E. Zhulina, "Modeling the interactions between polymers and clay surfaces through selfconsistent field theory," Macromolecules, vol. 31, no. 23, pp. 8370-8381, 1998.

[21] V. V. Ginzburg and A. C. Balazs, "Calculating phase diagrams of polymer-platelet mixtures using density functional theory: implications for polymer/clay composites," Macromolecules, vol. 32, no. 17, pp. 5681-5688, 1999.

[22] V. V. Ginzburg, C. Singh, and A. C. Balazs, "Theoretical phase diagrams of polymer/clay composites: the role of grafted organic modifiers," Macromolecules, vol. 33, no. 3, pp. 10891099, 2000.

[23] A. Usuki, Y. Kojima, M. Kawasumi et al., "Synthesis of nylon 6-clay hybrid," Journal of Materials Research, vol. 8, no. 5, pp. 1179-1184, 1993.

[24] P. B. Messersmith and E. P. Giannelis, "Synthesis and barrier properties of poly( $\varepsilon$-caprolactone)-layered silicate nanocomposites," Journal of Polymer Science, Part A: Polymer Chemistry, vol. 33, no. 7, pp. 1047-1057, 1995.

[25] T. J. Pinnavaia, T. Lan, Z. Wang, H. Shi, and P. D. Kaviratna, "Clay-reinforced epoxy nanocomposites: synthesis, properties, and mechanism of formation," in Nanotechnology: Molecularly Designed Materials, vol. 622 of ACS Symposium Series, pp. 250-261, 1996.

[26] P. B. Messersmith and E. P. Giannelis, "Synthesis and characterization of layered silicate-epoxy nanocomposites," Chemistry of Materials, vol. 6, no. 10, pp. 1719-1725, 1994.

[27] T. Lan, P. D. Kaviratna, and T. J. Pinnavaia, "Mechanism of clay tactoid exfoliation in epoxy-clay nanocomposites," Chemistry of Materials, vol. 7, no. 11, pp. 2144-2150, 1995.

[28] J. M. Brown, D. Curliss, and R. A. Vaia, “Thermoset-layered silicate nanocomposites. Quaternary ammonium montmorillonite with primary diamine cured epoxies," Chemistry of Materials, vol. 12, no. 11, pp. 3376-3384, 2000.

[29] M. S. Wang and T. J. Pinnavaia, "Clay-polymer nanocomposites formed from acidic derivatives of montmorillonite and an epoxy resin," Chemistry of Materials, vol. 6, no. 4, pp. 468-474, 1994.

[30] W. Ahlborn, "Vapor-phase polymerization of tetrafluoroethylene in the presence of fillers," US Patent 2847391, 1958.

[31] H. Z. Friedlander, "Homopolymer forms by contact polymerization on oxides or with Ziegler catalyst on clay," Chemical and Engineering News, vol. 42, p. 42, 1964.

[32] H. Z. Friedlander and C. R. Frink, "Organized polymerization. III. Monomers intercalated in montmorillonite," Journal of Polymer Science Part C: Polymer Letters, vol. 2, no. 4, pp. 475-479, 1964.

[33] A. Blumstein, "Etudes des polymerization en couche adsorbee," Bulletin De La Societe Chimique De France, no. 89, pp. 899-905, 1961.

[34] R. Blumstein, A. Blumstein, and K. K. Parikh, "Polymerization of monomolecular layers adsorbed on montmorillonite: cyclization in polyacrylonitrile and polymethacrylonitrile," Applied Polymer Symposia, no. 25, pp. 81-88, 1974.
[35] Y. Sugahara, S. Satokawa, K. Kuroda, and C. Kato, "Evidence for the formation of interlayer polyacrylonitrile in kaolinite," Clays and Clay Minerals, vol. 36, no. 4, pp. 343-348, 1988.

[36] F. Bergaya and F. Kooli, "Acrylonitrile-smectite complexes," Clay Minerals, vol. 26, no. 1, pp. 33-41, 1991.

[37] C. Kato, K. Kuroda, and H. Takahara, "Preparation and electrical properties of quaternary ammonium montmorillonitepolystyrene complexes," Clays and Clay Minerals, vol. 29, no. 4, pp. 294-298, 1981.

[38] D. J. Greenland, "Adsorption of polyvinyl alcohols by montmorillonite," Journal of Colloid Science, vol. 18, no. 7, pp. 647-664, 1963.

[39] C. W. Francis, "Adsorption of polyvinylpyrrolidone on reference clay minerals," Soil Science, vol. 115, no. 1, pp. 4054, 1973.

[40] R. L. Parfilt and D. J. Greenland, "The adsorption of poly(ethylene glycols) on clay minerals," Clay Minerals, vol. 8, no. 3, pp. 305-315, 1970.

[41] N. Schamp and J. Huylebroeck, "Adsorption of polymers on clays," Journal of Polymer Science: Polymer Symposia, vol. 42, no. 2, pp. 553-562, 1973.

[42] E. P. Plueddemann, Silane Coupling Agents, Plenum Press, New York, NY, USA, 2nd edition, 1991.

[43] E. Ruiz-Hitzky and J. J. Fripiat, "Organomineral derivatives obtained by reacting organochlorosilanes with the surface of silicates in organic solvents," Clays and Clay Minerals, vol. 24, no. 1, pp. 25-30, 1976.

[44] P. J. Flory, Principle of Polymer Chemistry, Cornell University Press, New York, NY, USA, 1967.

[45] M. W. Noh and D. C. Lee, "Synthesis and characterization of PS-clay nanocomposite by emulsion polymerization," Polymer Bulletin, vol. 42, no. 5, pp. 619-626, 1999.

[46] D. C. Lee and L. W. Jang, "Preparation and characterization of PMMA-clay hybrid composite by emulsion polymerization," Journal of Applied Polymer Science, vol. 61, no. 7, pp. 11171122, 1996.

[47] A. Vatansever, T. Inan, H. Dogan, and A. Sirkecioglu, "Effect of organic modifier type of montmorillonite on the poly (butyl acrylate-co-methyl methacrylate)/montmorillonite nanocomposite," Polymer Bulletin, vol. 73, no. 4, pp. 909-925, 2016.

[48] O. Yilmaz, C. N. Cheaburu, D. Durraccio, G. Gulumser, and C. Vasile, "Preparation of stable acrylate/montmorillonite nanocomposite latex via in situ batch emulsion polymerization: effect of clay types," Applied Clay Science, vol. 49, no. 3, pp. 288-297, 2010.

[49] M. Okamoto, S. Morita, H. Taguchi, Y. H. Kim, T. Kotaka, and H. Tateyama, "Synthesis and structure of smectic clay/ poly(methyl methacrylate) and clay/polystyrene nanocomposites via in situ intercalative polymerization," Polymer, vol. 41, no. 10, pp. 3887-3890, 2000.

[50] L. Biasci, M. Aglietto, G. Ruggeri, and F. Ciardelli, "Functionalization of montmorillonite by methyl methacrylate polymers containing side-chain ammonium cations," Polymer, vol. 35, no. 15, pp. 3296-3304, 1994.

[51] J. G. Doh and I. Cho, "Synthesis and properties of polystyreneorganoammonium montmorillonite hybrid," Polymer Bulletin, vol. 41, no. 5, pp. 511-518, 1998.

[52] F. Dietsche, Y. Thomann, R. Thomann, and T. Mulhaupt, "Translucent acrylic nanocomposites containing anisotropic laminated nanoparticles derived from intercalated layered 
silicates," Journal of Applied Polymer Science, vol. 75, no. 3, pp. 396-405, 2000.

[53] M. W. Weimer, H. Chen, E. P. Giannelis, and D. Y. Sogah, "Direct synthesis of dispersed nanocomposites by in situ living free radical polymerization using a silicate-anchored initiator," Journal of the American Chemical Society, vol. 121, no. 7, pp. 1615-1616, 1999.

[54] X. Huang and W. Brittain, "Synthesis of a PMMA-layered silicate nanocomposite by suspension polymerization," Polymer Preprints, vol. 41, no. 1, pp. 521-522, 2000.

[55] S. Bandyopadhyay, E. P. Giannelis, and A. Hsieh, "Thermal and thermomechanical properties of PMMA nanocomposites," Polymeric Materials Science and Engineering, vol. 82, pp. 208-209, 2000.

[56] J. Yan and F. Zhou, " $\mathrm{TiO}_{2}$ nanotubes: structure optimization for solar cells," Journal of Materials Chemistry, vol. 21, no. 26, pp. 9406-9418, 2011. 


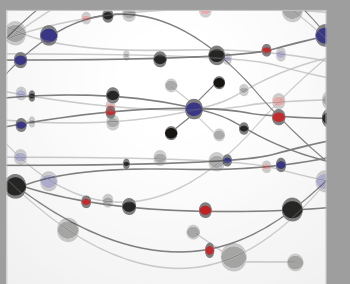

The Scientific World Journal
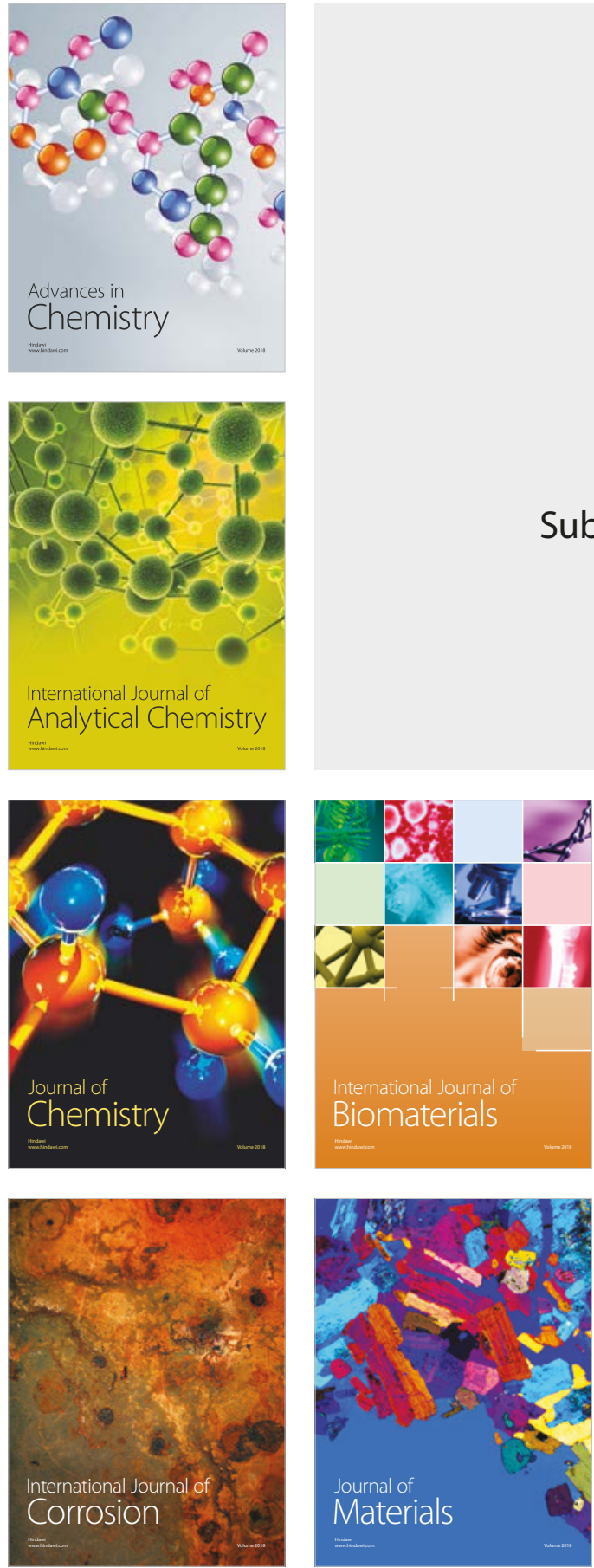

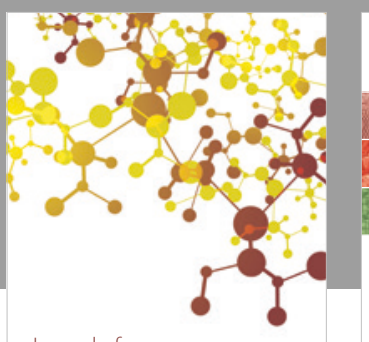

Journal of

Applied Chemistry
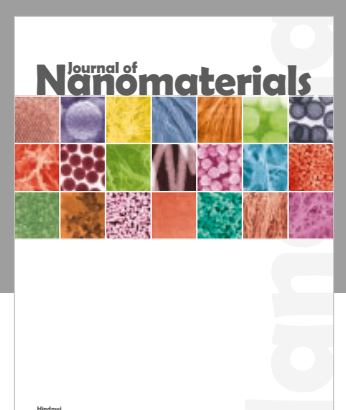

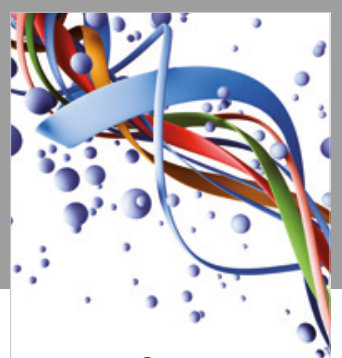

Scientifica

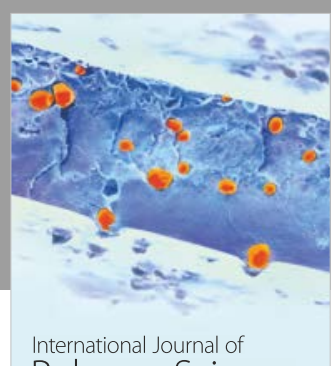

Polymer Science

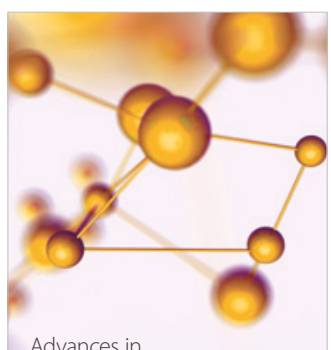

Physical Chemistry
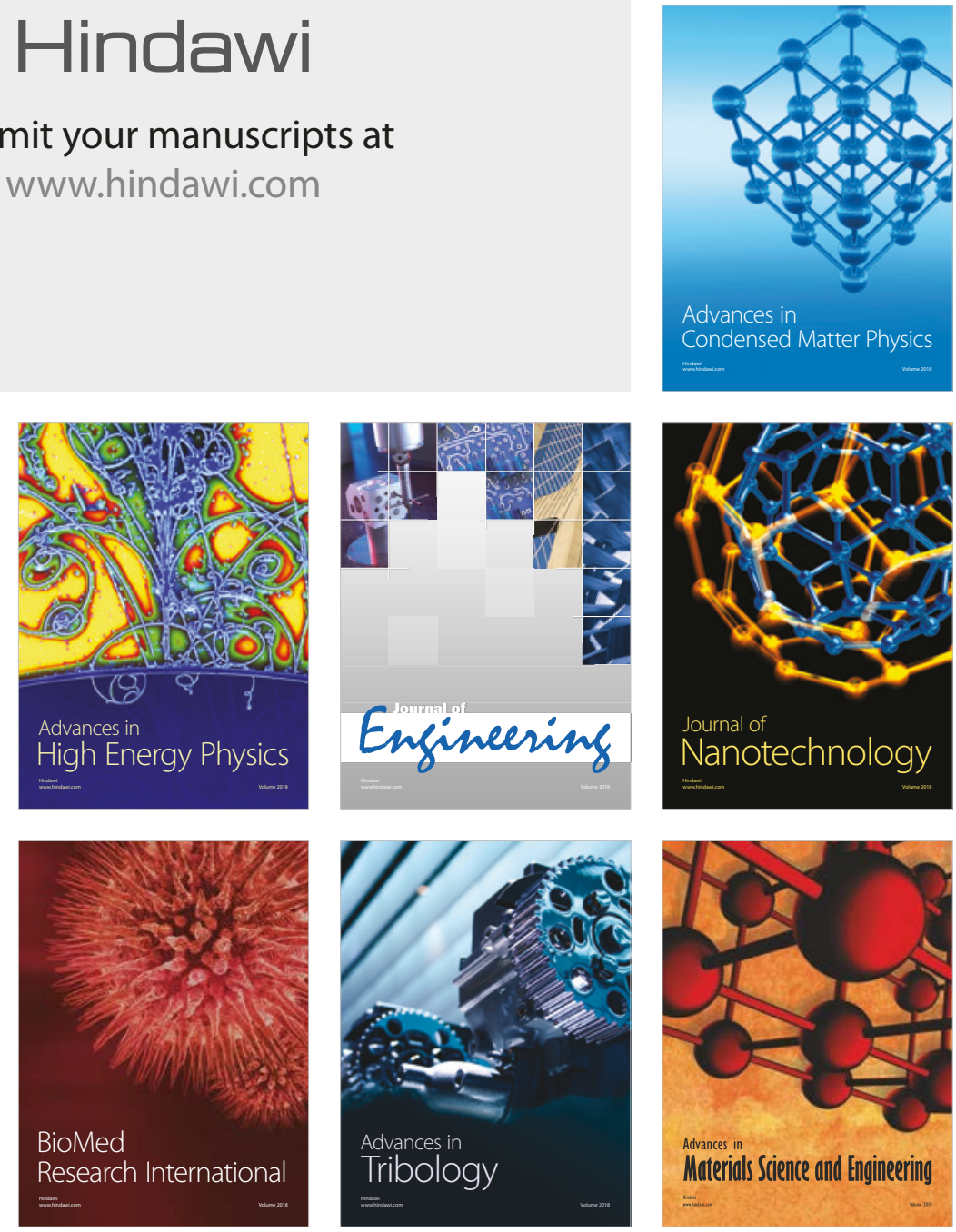